\title{
ESTRATÉGIA ORGANIZACIONAL VOLTADA PARA A LUCRATIVIDADE E SUSTENTABILIDADE: UM ESTUDO DE CASO
}

\author{
ORGANIZATIONAL STRATEGYTO LUCRATIVITY \\ AND SUSTENTABILITY: A CASE-STUDY
}

André Sarmento Spalenza Doutorando em Administração (Universidade Federal da Bahia/Brasil).E-mail: andrespalenza@gmail.com
Mariana Amorim de Amaral

Mestre em Administração (Universidade federal do Espirito Santo/Brasil).E-mail: mariana.amorim.amaral@gmail.com. 


\section{RESUMO}

Este estudo de caso tem como objetivo analisar como as estratégias organizacionais se relacionam com o lucro e a sustentabilidade. Por sustentabilidade, entende-se que é o tratamento igualitário do crescimento econômico, preservação ambiental e desenvolvimento social. O estudo foi realizado por meio de uma abordagem qualitativa, através de análise de caso único. Os dados foram coletados através do método de triangulação de dados, que neste caso foi composto por: pesquisa documental, entrevistas e observação. A pesquisa documental consiste na averiguação de documentos, tais como o site, licenças, relatórios anuais, dentre outros. A entrevista foi em profundidade e semiestruturada, sendo os entrevistados membros da organização que ocupam cargos de decisão. A observação foi assistemática não participante. O principal resultado encontrado foi: a relação não positiva entre lucratividade e sustentabilidade, mas sim a relação entre lucratividade e responsabilidade social corporativa. O trabalho teve como limitação o fato de estudar apenas uma organização, não sendo possível a análise de outras de setores diferentes do de sustentabilidade.

Palavras-chave: Organizações. Gestão. Estratégia. Lucratividade. Sustentabilidade.

\section{ABSTRACT}

This case study aims to examine how the organizational strategies are articulated with the lucrativity and sustainability. For sustainability it is understood that is the equal treatment of economic growth, environmental preservation and social development. The study was performed by a qualitative approach. The data were collected through data triangulation method, which in this case was composed of: desk research, interviews and observation. The documentary research is the investigation of documents, such as site licenses, annual reports, among others. The interview was in-depth and semi-structured, and the interviewed were members of the organization who occupied decision-making positions. The observation was unsystematic and nonparticipant. The main results were not positive relationship between profitability and sustainability, but the relationship between profitability and corporate social responsibility. This research have as limitation the fact of the study only researchs one organization, beeing not possible to analyze other different sectors instead of the sustainability one.

Keywords: Organizations. Business. Strategy. Lucrativity. Sustainability. 


\section{INTRODUÇÃO}

Trata-se de um estudo que se propõe a investigar como a estratégia organizacional se relaciona a dois objetivos organizacionais: lucro e sustentabilidade. Ao falar de sustentabilidade, englobam-se os conceitos de desenvolvimento sustentável (DS) e Responsabilidade social corporativa (RSC).

O presente trabalho parte do pressuposto de que a organização é um sistema social aberto que influencia e é influenciada por variáveis desconhecidas e não controláveis, cujas consequências são probabilísticas e não determinísticas. Os sistemas abertos sofrem constantes adaptações e modificações, não estando em repouso e sim em constante modificação (HITT; IRELAND; HOSKISSON, 2008). Considerar a organização como um sistema social aberto, composta por fatores internos e externos permite ancorar a discussão da estratégia organizacional e da sustentabilidade no contexto deste artigo.

Este trabalho, entendendo a organização como um sistema social aberto, explora duas temáticas relevantes no campo dos estudos organizacionais: estratégia e sustentabilidade. A estratégia é um campo de conhecimento amplo, controverso e que permite diversas perspectivas conceituais, dimensões e abordagens. A despeito de toda essa diversidade, parece haver no campo o entendimento de que duas perspectivas polarizam as discussões sobre estratégia: a sociológica e a econômica (RUMELT; SCHENDEL; TEECE, 1994). Rumelt, Schendel e Teece (1994) definem a abordagem sociológica como a busca para entender as diversas dimensões da organização, como estrutura e processos, e a perspectiva econômica focando no entendimento da estratégia como instrumento de maximização da eficiência. Esse estudo ancora-se na abordagem econômica por tratar de eficiência organizacional e lucratividade.

Entendendo estratégia pela vertente econômica, com a função de maximizar a eficácia, Hobsbawm (1995) indica que as normas socialmente estipuladas para as organizações até meados dos anos 70 permitiam às organizações exercerem atividades em que a única preocupação era o lucro. A partir da década de 70, porém, a sociedade começa a perceber que as normas até então vigentes não eram mais adequadas, pois estavam acarretando degradação ambiental e social, o que levou ao debate sobre a sustentabilidade e o DS. As estratégias empresariais utilizadas, que tinha unicamente a preocupação econômica, passaram a perder a credibilidade por não serem mais socialmente aceitas, o que levou às organizações a buscarem novas estratégias no intuito de atender as exigências formadas por um novo contexto, o da preocupação com o social e o ambiental (HOBSBAWN, 1995).

Atualmente, no contexto social e organizacional, discute-se a importância da sustentabilidade, na qual, ao mesmo tempo em que a organização deve buscar o lucro, tem também por obrigação garantir o bem 
estar das gerações atuais e futuras, através de ações de cunho sustentável. Organizações que não buscam a sustentabilidade não possuem suas atividades legitimadas pela sociedade, o que as fazem perder clientes ou até mesmo serem impedidas de atuar em determinado setor (BRONDANI; HENZEL, 2010; ONARAN, 2010; VASCONCELOS; ALVES; PESQUEUX, 2012; PATTI; SILVA; ESTENDER, 2015; HEPPER; BENT; SANTOS, 2016).

Aparentemente a conciliação desses dois temas apresenta-se como um desafio que vem sendo discutido por diversos autores nos estudos organizacionais. Pesquisadores empíricos ainda discutem se é possível o alcance da lucratividade juntamente com a sustentabilidade (MCWILLIAMS; SIEGEL, 2011). Friedman (1970) argumenta que não é possível equilibrar estes elementos, ao passo que Husted e Allen (2012) apontam que a estratégia corporativa vai além do nível econômico e deve equilibrar o lucro com a sustentabilidade.

Diante de divergentes perspectivas apontadas pela literatura: a primeira de que não é possível o alcance da lucratividade e da sustentabilidade (FRIEDMAN, 1999) e a segunda de que há a possibilidade de se alcançar esses dois elementos (HART, 1995), é observado um contexto específico de um aterro sanitário, em que o alcance desses dois elementos não só é possível, mas necessário, sendo uma exigência para a atividade em questão (BESEN et al., 2010; FARIA, 2002).

Defende-se neste trabalho a relevância de investigar como a estratégia empresarial está relacionada ao alcance de dois resultados aparentemente contraditórios: lucro e sustentabilidade, Pautando-se principalmente no que é dito em Hart (1995) e Arend e Lévesque (2010) e levando em consideração as particularidades do contexto estudado, um aterro sanitário. Neste artigo parte-se do pressuposto de que é viável e necessário conciliar lucro e sustentabilidade.

Diante dessas contribuições teóricas e evidências empíricas, propõe-se o seguinte problema de pesquisa: Como as estratégias organizacionais se relacionam com a lucratividade e a sustentabilidade no contexto de um aterro sanitário? Definiu-se como objetivo para a pesquisa, descrever e analisar como as estratégias organizacionais se relacionam com a lucratividade e a sustentabilidade no contexto de um aterro sanitário.

Segundo Vasconcelos, Silva Junior e Silva (2013), Vizeu, Meneghetti e Seifert (2012), Maia e Pires (2011), Senge et al. (2009), Sachs (2008), Penteado (2003), Hepper, Bent e Santos, 2016 entre outros, o modelo econômico tradicional caracterizado pelo processo produtivo que visa somente o lucro econômico está sendo substituído por um modelo sustentável o qual é caracterizado pela conscientização de que os recursos são escassos e limitados, devendo o ciclo econômico estar associado à ecologia do planeta, ao contexto sociocultural, político, tecnológico e ao mercado, bem como à orientação de longo prazo de forma a alcançar futuras gerações e o bem estar socioambiental. 
Ao relacionar estratégia com a lucratividade e sustentabilidade, este artigo contribui para o campo de pesquisas em estratégia que, historicamente tem realizado estudos sob a perspectiva do modelo econômico tradicional de industrialização que pressupunha a utilização indiscriminada dos recursos para alcançar vantagem competitiva e lucratividade. Olhar a utilização dos recursos da organização para a obtenção de vantagem competitiva por meio da lente do modelo econômico tido como sustentável implica em assumir que a vantagem competitiva deixa de ser exclusivamente econômica para alcançar também as dimensões social e ambiental (VEIGA; TORTATO, 2014; VASCONCELOS; SILVA JUNIOR; SILVA, 2013; VIZEU; MENEGHETTI; SEIFERT, 2012; MAIA; PIRES, 2011; SENGE et al., 2009; SACHS, 2008; PENTEADO, 2003; HART, 1995; PETERAF, 1993; BARNEY, 1991; WERNERFELT, 1984.; HEPPER; BENT; SANTOS, 2016).

A articulação entre as perspectivas teóricas da estratégia e da sustentabilidade tem sido pouco explorada por autores no contexto brasileiro. Por exemplo, Veiga e Tortato (2014) investigaram e constataram a presença de paradoxos entre os discursos organizacionais sobre sustentabilidade com conotação altruísta e a postura estratégica organizacional adotada em termos de sua capacidade de promover a manutenção do meio ambiente e a qualidade de vida.

\section{MATERIAL E MÉTODO}

Para conduzir o estudo, adotou-se a estratégia de pesquisa qualitativa (TRIVIÑOS, 2009) por meio do método do estudo de caso único, com abordagem descritiva (YIN, 2015). Apoiado em Yin (2015), a escolha do método justifica-se em razão do caso estudado ser considerado peculiar e com características exclusivas. Conforme já destacado anteriormente na introdução, o caso investigado é o de uma organização que se configura como um aterro sanitário com processo único de manuseio integrado de resíduos tem exclusividade no Estado do Espírito Santo para comercializar cotas de carbono e atua em um contexto que oferece riscos à população, ao ambiente e à sociedade em geral. Em razão dos prejuízos sociais e ambientais decorrentes desses riscos, esse tipo de organização sofre controle do governo e da sociedade que exigem soluções orientadas para a sustentabilidade (BESEN et al., 2010; HUSTED; ALLEN, 2010; FARIA, 2002). A fim de não identificar a organização pesquisada, optou-se pela utilização de um nome fictício, qual seja, "Kappa”.

No presente estudo foi utilizada a técnica de triangulação de dados, que, segundo Flick (2005), é a combinação de elementos extraídos de diferentes fontes em um mesmo estudo. Utilizou-se a forma within-method de triangulação, a qual é apontado por Denzin (2003) como técnicas diferentes sendo utilizadas em um mesmo método, tratando-se os resultados em conjunto e de forma complementar. Esta técnica coloca em confronto os dados extraídos, o que possibilita utilizar de virtudes e dirimir as limitações de cada fonte (DENZIN, 2003). 
A triangulação de dados através do within-method possibilitou a visualização de elementos contraditórios que representam invalidade, bem como o complemento de informações as quais não seriam possíveis de serem constatadas acaso fosse utilizada somente uma fonte ou se as fontes fossem tratadas de forma isolada. No presente trabalho, as fontes utilizadas foram: documentos, entrevistas semiestruturadas e análise observacional assistemática não participante.

Os dados extraídos de documentos foram utilizados em dois momentos, primeiramente como dados secundários e em um segundo momento como dados primários, sendo tratadas como fontes de informação conjunta as entrevistas e as observações.

Os entrevistados foram membros da organização que ocupam cargos de gestão. A escolha dos entrevistados foi por conveniência e baseada na intencionalidade. Como aponta Gaskell (2008), esse método de escolha considera a acessibilidade que o pesquisador possui e o interesse do pesquisado. No presente estudo foram identificados os gestores que influenciam a estratégia organizacional e as entrevistas ocorreram na medida em que estes tiverem disponibilidade de responder. A organização é composta por 02 diretores e 09 gerentes. Foram realizadas inicialmente 02 entrevistas em caráter preliminar a fim de se confeccionar o guia de entrevistas, conforme exposto na tabela abaixo:

Tabela 1 - Entrevistas preliminares

\begin{tabular}{|l|l|l|}
\hline Entrevistados & Função & Tempo de Empresa \\
\hline EP 01 & Colaborador & 4 anos \\
\hline EP 02 & Encarregado de operações & 5 anos \\
\hline
\end{tabular}

Fonte: Dados da pesquisa

Depois de realizadas as entrevistas preliminares, foram procedidas 07 outras entrevistas, 02 com ocupantes de cargo de diretoria e 05 com gerentes, seguindo o critério de saturação, conforme identificado na tabela abaixo. 
Tabela 2 - Entrevistas

\begin{tabular}{|l|l|l|}
\hline Entrevistados & Função & Tempo de empresa \\
\hline E 01 & Gerente de operações & 13 anos \\
\hline E 02 & Gerente de operações & 5 anos \\
\hline E 03 & Gerente de infra-estrutura & 4 anos \\
\hline E 04 & $\begin{array}{l}\text { Gerente de qualidade e meio } \\
\text { ambiente }\end{array}$ & 11 anos \\
\hline E 05 & Gerente de desenvolvimento & 3 anos \\
\hline E 06 & Superintendente & 3 anos \\
\hline E 07 & Diretor geral & 8 anos \\
\hline
\end{tabular}

Fonte: Dados da pesquisa

A observação foi feita de forma assistemática e não participante (YIN, 2005). Os principais elementos observados foram: O espaço físico, os processos e como estes eram realizados, levando-se em consideração os funcionários, como estes realizavam a tarefa e suas impressões e comentários acerca desta (YIN, 2005). A observação, no presente estudo, ocorreu na forma de visitas agendadas à organização, aonde o pesquisador conheceu e visualizou seus processos e estabelecimentos junto ao encarregado de operações.

Conforme indicou Bardin (2006), a análise dos dados foi feita através de categorias estabelecidas de forma mista, sendo estipuladas categorias iniciais, que não eram de caráter fixo, baseadas na literatura pesquisada. A fim de responder o problema de pesquisa e atender o objetivo do trabalho, as categorias estabelecidas foram: estratégia, lucratividade e sustentabilidade.

A categorização dos dados extraídos das entrevistas, conforme indica Bardin (2006), pode ocorrer através do conteúdo ou das palavras semelhantes nas falas. Optou-se por realiza-la conforme o conteúdo, em que as matérias de falas semelhantes foram postas em uma mesma categoria, ainda que as palavras utilizadas não tenham sido as mesmas. 


\section{APRESENTAÇÃO E ANÁLISE dOS DADOS}

\subsection{O CONTEXTO DE ATUAÇÃO DA KAPPA}

A organização estudada está inserida no setor de sustentabilidade, sendo seu foco de atuação a gestão de resíduos de forma ambiental e socialmente responsável. A organização atua junto com clientes públicos e privados oferecendo a eles soluções para os resíduos oriundos de suas atividades.

A organização foi idealizada no inicio dos anos 1990, em um contexto no qual os resíduos sólidos, no Estado do Espirito Santo, não recebiam a devida atenção, havendo uma grande quantidade de lixões, onde não eram realizadas operações em que os resíduos pudessem ser tratados a fim de evitar prejuízos à natureza e à sociedade, sendo o lixo coletado despejado em córregos, canais de rios e em mangues. Nessa época 50,8\% das cidades da Grande Vitória depositavam seus resíduos em lixões (IBGE, 2014), onde populações marginalizadas, até mesmo crianças, buscavam extrair dali seu sustento, em condições degradantes.

Após a Conferência Rio 1992, a gestão de resíduos sólidos foi um tema que passou a ser tratado juntamente com a sustentabilidade, estipulando-se que esta atividade somente deveria ser feita através de processos que levassem em conta a natureza e a sociedade, em equilíbrio com o lucro organizacional (ONU, 2009). Governos e municípios passam a ter maiores responsabilidades quando o assunto é gestão sustentável dos resíduos, sendo responsáveis por criarem mecanismos de coleta seletiva, reaproveitamento do lixo, reciclagem, dentre outros, com escopo de diminuir o impacto negativo que a disposição de resíduos gera para a natureza e sociedade (JACOBI; BESEN, 2011; GARCIA et. al., 2016).

A Lei No 11.445, de 2007, define, de maneira especifica, as diferentes formas de coleta e tratamento dos resíduos, e responsabiliza o município por essas atividades (JACOBI; BESEN, 2006). Os municípios, porém, não são competentes, por si só, para realizar a atividade, e a terceirizam, conforme autorizado pela lei (JACOBl; BESEN, 2011). Porém, como indicam Jacobi e Besen (2011), a terceirização torna os municípios responsáveis pela fiscalização da atividade e os responsabiliza pela contratação da terceirizada.

Para que a atividade de gerenciamento de resíduos seja executada, a organização contratada deve seguir rigorosamente os processos exigidos em lei, bem como ser uma organização legitimada pela sociedade e pelo município, sendo o menor deslize ou o não cumprimento das diretrizes estabelecidas, responsáveis pelo fim do contrato de serviço.

São diretrizes estabelecidas pela Lei № 11.445, de 2007, que devem ser fiscalizadas pelos municípios: "a prevenção, precaução, redução, reutilização e reciclagem, metas de redução de disposição final de resíduos 
em aterros sanitários e a disposição final ambientalmente adequada dos rejeitos em aterros sanitários" (JACOBI; BESEN, 2011, p. 137). No que tange a sustentabilidade, Jacobi e Besen (2011) ressaltam que a legislação exige da organização que esta incentive e ofereça benefícios às organizações de catadores e crie centrais de estocagem e comercialização de produtos reciclados.

No Estado do Espirito Santo, a Política Estadual de Resíduos Sólidos (Lei No 9.264, 2009) confere aos municípios a responsabilidade de promoverem ações de saneamento básico, as quais são estabelecidas através de leis orgânicas. No caso específico de Cariacica, onde se insere a organização estudada, as normas no âmbito municipal são estabelecidas pela Lei orgânica n. 5.283, de 17 de novembro de 2014, que permite a uma organização realizar os serviços de coleta, transporte e disposição final por meio do devido processo licitatório.

Assim como é exigida ao município a correta disposição de resíduos, também exige-se a mesma medida às organizações privadas, não podendo estas despejarem seus detritos em córregos ou lixões a céu aberto, mas os destinar a locais em que não serão prejudiciais ao meio ambiente e à sociedade. (ESPIRITO SANTO, 2009). Além da legislação aplicada, as organizações privadas são socialmente responsabilizadas e cobradas a possuírem atividades que busquem a sustentabilidade, obtendo, por meio destas atitudes, legitimidade social, o que contribui para a aceitação e valorização da marca. No setor privado, portanto, a destinação responsável dos resíduos vai além de seguir a legislação, porquanto, contribuem também para a imagem organizacional (HAMEL; PRAHALAD, 1995; AZEVEDO; VON ENDE; WITTMANN, 2016).

A destinação, entretanto, é uma atividade custosa e de difícil realização, sendo assim, acaba por ser terceirizada. Organizações públicas e privadas, na tentativa de tornarem suas atividades sustentáveis, buscam organizações especializadas, atestadas através de licenças e que possuem imagem estabelecida no mercado para realizarem a destinação final de resíduos de forma sustentável (FARIA, 2002, GARCIA et. al., 2016).

Neste contexto se insere a Kappa, que funciona como viabilizadora da sustentabilidade de outras organizações, que por si só, não são competentes para realizarem a própria destinação final de resíduos. A organização pesquisada utiliza de seus recursos internos para oferecer serviços de forma diferenciada e diversificada, que propiciam as organizações contratantes o exercício de sua atividade de forma sustentável.

No mercado em que se insere a Kappa, o tratamento dos diversos tipos de resíduos só é possível de se realizar através das licenças ambientais conseguidas no IEMA, órgão responsável pelo licenciamento e fiscalização de empreendimentos que realizam atividades potencialmente poluidoras. Para o licenciamento de qualquer operação que envolve gerenciamento de resíduos, são vários processos, que envolvem grande custo. 
No setor em questão, antes de se realizar a atividade, primeiro é necessário possuir licença de implantação, com a apresentação do projeto a ser implantado, que deve estar de acordo com a legislação e com os parâmetros estabelecidos pelo IEMA. Após a licença de implantação, deve-se conseguir a licença de operação, a qual é concedida se o IEMA considerar que a organização possui pessoal e maquinário que garantem a realização da atividade sem oferecer riscos ao meio ambiente e a sociedade.

Devido às dificuldades de entrar no setor e as grandes exigências em relação a estrutura e licenças, quando o gerenciamento responsável de resíduos passou a ser uma exigência no Estado do Espirito Santo, poucas organizações estavam aptas a atuar nesta área, fato este que tem se modificado ao passar dos anos, com a entrada de organizações que veem no setor uma oportunidade.

Atualmente a organização tem como atividades base a coleta e a disposição final de resíduos em células, sendo que para alguns resíduos, a organização realiza o tratamento final, considerando a viabilidade técnica, financeira, operacional e legislação aplicável. Através de maquinários específicos e processos físicos e químicos, a organização devolve à natureza os resíduos. Sendo os principais, o biogás, fluidos de perfuração, fossas, iodo e chorume.

Além das atividades base, a organização presta, ainda, serviços de ordem social que são benéficos para a população local e meio ambiente, não sendo lucrativos. Os serviços sociais são: educação ambiental, parque de econegócios, espaço canal aberto, projetos socioambientais e programa de ressocialização de ex-presidiários.

As atividades base e os projetos sociais fazem parte da estratégia da organização para o alcance da vantagem competitiva. As atividades base conferem lucro para a organização pelo serviço prestado, enquanto as sociais viabilizam a estratégia de imagem, o que proporciona aumento da lucratividade em longo prazo. As atividades organizacionais formam as competências essenciais e estas contribuem para a geração da vantagem competitiva.

A organização utiliza de meios para manter-se a frente da concorrência e alcançar o diferencial competitivo. Tais meios são chamados por Seth e Thomas (1994) de estratégias organizacionais, que fazem interagir todos os stakeholders para que os retornos alcançados sejam maiores que os custos implantados.

A fim de alcançar a vantagem competitiva, a organização pesquisada utiliza de estratégias, das quais, as principais identificadas foram: inovação, diferenciação, imagem e diversificação. Tais estratégias geram ou geraram em algum momento vantagem para a organização. 


\subsection{ESTRATÉGIAS ORGANIZACIONAIS}

\subsubsection{Inovação}

A estratégia de Inovação foi identificada na organização, pois esta se preocupa em lançar no mercado serviços inéditos. A Kappa iniciou suas atividades de forma pioneira, lançando o aterro sanitário. Atualmente, como a técnica de aterragem não é mais considerada inédita, sendo amplamente conhecida pelo mercado, a organização lança um novo serviço, o de tratamento de efluentes, até então inédito no Espirito Santo.

Zacccarelli e Fischmann (1994) definem a estratégia de inovação como aquela em que a organização lança no mercado serviços/produtos novos, o que pode gerar a extinção de um serviço/produto já existente. A atividade pioneira, o aterro sanitário lançado em 1995, no município de Cariacica, fez com que a organização fosse a única no município preparada para o tratamento integrado de resíduos sólidos, o que a concedeu o direito, mantido até hoje, de realizar os serviços de aterragem dos resíduos sólidos do município. Antes do lançamento do aterro em questão, os resíduos eram despejados em lixões a céu aberto, o que parou de acontecer, levando a extinção gradativa dos mesmos.

Ao perceber que a concorrência se ampliava, quando outras organizações passaram a realizar atividades que antes eram exclusivas da organização pesquisada, esta lançou um novo serviço, o tratamento de efluentes, que não é realizado por nenhuma outra organização no Espirito Santo.

Existe uma dificuldade de se estabelecer negócios desse tipo aqui no estado, pela legislação, que tem uma série de exigências, pelo capital inicial, que é grande, e pelo grande investimento no geral, mas mesmo com essas barreiras, hoje já têm um monte de organizações no mercado, o que não tinha antigamente, e a tendência é aumentar esse número [...] Como a concorrência cresce, temos que nos atualizar, para estar sempre com algo novo (E 05).

O pioneirismo da organização, que se deu pelo fato da Kappa ser a única a realizar a atividade de aterragem seguindo os padrões de sustentabilidade estipulados nacionalmente, os quais os municípios eram pressionados a aderir, logo foi alcançado por outras organizações, que viram no setor uma oportunidade de negócio e passaram a realizar a mesma atividade, de forma semelhante.

\subsubsection{Diferenciação}

A estratégia de diferenciação, para Zaccarelli e Fischmann (1994) ocorre quando uma organização consegue oferecer um produto/serviço de modo que as outras não oferecem. A diferenciação, para os autores, 
é constantemente utilizada após a inovação, de modo que o diferencial competitivo de determinada organização esteja sempre à frente das concorrentes.

Como descrito em Zaccarelli e Fischmann (1994), a Kappa utiliza da diferenciação de seus serviços para se manter à frente da concorrência. Através da análise do histórico da organização, percebe-se que esta, desde a sua fundação, lança um produto inovador, o aterro sanitário, porém, ao passo que a concorrência passava a copiar as técnicas, aquela inovava, não lançando um novo serviço, mas melhorando na realização do serviço que já era prestado. A diferenciação dos serviços funciona como barreira de entrada e como melhoria da imagem institucional perante os clientes.

A barreira de entrada criada pela inovação se reflete na legislação aplicada. A legislação, no setor de sustentabilidade, influencia as organizações, porém também é influenciada por elas (BARTOLOMEO; SILVA; FONSECA, 2014).

A presente organização influencia a legislação ao realizar soluções inovadoras, o que é explicado por Bartolomeo, Silva e Fonseca (2014) e Cirelli e Kassai (2010), que indicam que a legislação pode ser influenciada quando uma organização consegue realizar algo que seja sustentável, pois considera-se que, se uma organização consegue realizar esta solução, as demais assim também devem fazer a fim de contribuirem para uma sociedade mais sustentável. Por se tratar de um mercado novo e não estabelecido por completo, ações sustentáveis inovadoras, que não são exigidas por lei, mas se realizadas, por existir uma tendência dos governos e sociedades na busca de alcançar o DS, influenciam a legislação, vindo a fazer parte dela (CIRELLI; KASSAI, 2010).

\subsubsection{Imagem}

No que se refere a clientes privados, o beneficio em imagem ocorre no sentido de que as soluções oferecidas pela organização vão além daquelas exigidas pela legislação, de modo que grandes organizações a procuram a fim de, mais do que cumprirem a legislação, investirem na imagem institucional, indo de acordo com o que é dito em Hart (1995), no sentido de que a imagem constitui um importante bem intangível que influencia a vantagem competitiva. Clientes privados buscam soluções ambientais e socialmente responsáveis na organização, a fim de mostrar ao público que não são organizações poluidoras e sim sustentáveis.

A imagem foi apontada por Hart (1995) como sendo um benefício advindo de atividades sustentáveis, que não implicam diretamente no lucro. Hart (1995) aponta para a atividade voluntária como a principal beneficiadora da imagem, em que a organização passa a ser vista pela sociedade e clientes como socialmente responsável. 
No caso específico da Kappa, acredita-se que as atividades voluntárias são importantes para a melhoria da imagem organizacional, porém, em menor grau do que a atividade fim da organização, que se acredita ser a maior responsável por gerar reais benefícios ambientais e sociais, conforme descrito a seguir:

[...] O maior benefício que a gente acredita que presta não são as atividades sociais, mas é retirar o resíduo, que poderia ser lançado no mar, em terrenos baldios [...]. A marca retira esses resíduos da sociedade e presta um serviço sustentável, para o meio ambiente e para a sociedade, isso acredito que seja nossa contribuição [...] Pensamos no lucro, mas o lucro só vem se fizermos tudo direitinho, de forma sustentável. As atividades sociais são importantes, mas não adiantaria nada fazer atividade social se fizermos o tratamento dos resíduos de forma errada [...] (E 07).

No caso das organizações que procuram as atividades da organização, isso ocorre, pois, os benefícios em imagem são a longo prazo, porém, na organização pesquisada, o benefício é imediato, com implicação direta no lucro. Por esta organização estar inserida no setor de sustentabilidade, ela lucra ao realizar atividades que são benéficas para a imagem dos clientes.

A possibilidade de agregar quando se fala da imagem dos clientes, exige que a organização possua uma imagem legitimada no mercado, como realizadora de soluções responsáveis. Tal fato é descrito por Bartolomeo, Silva e Fonseca (2014), Garcia et. al., 2016 e também por Azevedo, Von Ende e Wittmann (2016) que falam que uma organização inserida em setor de risco deve estar em permanente alerta com suas atividades, pois, caso não estejam e a atividade realizada for considerada nociva para a sociedade e meio ambiente, aquela tem grandes perdas referente a sua imagem pública e de mercado.

O que torna a Kappa apta a contribuir para a melhoria da imagem dos clientes é a sua própria imagem, que funciona como forma de estratégia organizacional. Ao ser reconhecida pela sociedade e pelo mercado, a organização capta mais clientes, em função de sua boa imagem corporativa. Tal legitimidade é atestada através dos prêmios de excelência e reconhecimento pelos serviços prestados. Além do reconhecimento pela atividade base, atividades de cunho social e ambiental, que não são lucrativas, também influenciam na melhoria da imagem organizacional.

\subsubsection{Diversificação}

Ao questionar os entrevistados sobre a geração de valor para a organização através de sua cadeia de atividades, percebe-se que uma das formas de se alcançar o diferencial competitivo é o fato daquela ser a única no mercado que oferece tratamento de resíduos de forma integrada, fazendo desde a coleta até a 
disposição final, com a preocupação de agregar aos serviços soluções não oferecidas pela concorrência. Como é visto em E 06:

\begin{abstract}
A gente procura sempre novidades no mercado, inspirados no que já está sendo feito em outros lugares, ou vendo algo que identificamos que está faltando aqui [...] O mercado é bastante instável, por isso a gente se preocupa em sempre trazem novidades para a nossa organização, isso sempre levando em consideração a viabilidade financeira e a sustentabilidade, claro.
\end{abstract}

Os lucros decorrentes das atividades da organização vêm do trabalho direto para com o cliente, seja ele público ou privado, o que foi concordado por todos, e mesmo com o custo sendo bastante alto, o lucro também é. Não são todas as atividades que são lucrativas, porém, o fato de uma atividade não gerar lucratividade não significa que ela deixará de ser feita, se for importante estrategicamente.

Um exemplo citado, de atividade que não gera lucro foi o tratamento de biogás, a qual exige maquinários modernos e não possui tanta procura, porém, se tratando de uma organização que presta diversos serviços, a atividade em questão é equilibrada por outras que geram lucro muito maior que o custo, suprindo eventual prejuízo financeiro. Tal atividade é importante para a organização, por fazer parte da cadeia de produtos oferecidos, agregando no quesito imagem, como expresso em E 05:

O tratamento de biogás, por exemplo, gera lucro praticamente zero, mas temos que fazer, porque se o cliente quer essa atividade, a gente tem que atender, mesmo que não ganhemos com isso, ou até mesmo tenhamos gastos [...] mas isso não nos prejudica de forma alguma, porque o lucro das outras atividades acaba por cobrir o que fazemos apenas por obrigação.

\title{
4.2 RESULTADOS ORGANIZACIONAIS
}

Ao serem questionados sobre a lucratividade da organização, os entrevistados percebem que, apesar dos altos custos, a organização é bastante lucrativa. Os custos, por serem altos, restringem a concorrência, fazendo com que as poucas organizações do setor consigam entrar (BENSEN et al., 2010). No caso da organização estudada, a lucratividade se intensifica, pois, além de estar em um setor altamente lucrativo, realiza atividades de forma exclusiva e diferenciada.

Ao tratarem sobre lucratividade, natureza e sociedade, os respondentes consideram que a organização trata por igual todos estes elementos, pois entendem que o seu negócio só consegue ser lucrativo se atender a 
natureza e a sociedade. É entendido pela organização que esta dedica-se de forma responsável à natureza e à sociedade, pois seu lucro vem desses elementos.

Pensamos sempre no lucro, como todas as organizações, mas levamos em consideração a natureza e a sociedade sim [...] nossa atividade é lucrativa sim, mas só temos lucro se formos sustentáveis, o que também é exigido pela lei, e não é um lucro que passamos por cima de qualquer coisa para obter, temos como principio considerar a natureza e as pessoas para sermos lucrativos [...] muitas empresas burlam a lei e são falsamente sustentáveis, a gente não, mesmo porque uma hora ou outra elas vão pagar o preço por fazer isso (E 07).

As atividades que vão além do escopo principal, que são realizadas de forma voluntária e sem lucro, não são vistas como sustentáveis, mas sim como um complemento que a organização pode fazer. Tais atividades ocorrem e são percebidas pelos membros da organização como benéficas, mas também enxergadas como algo que é feito a mais, sendo que a sustentabilidade é vista, pelos entrevistados, como alcançada na realização responsável das atividades fins.

A organização pesquisada está inserida no setor de sustentabilidade, que no Brasil é algo novo e intensamente regulamentado. Iniciado após a conferência RIO, 1992 (ONU, 2009), as organizações, de qualquer tipo, são exigidas a realizar ações sustentáveis, o que faz com que se destaquem organizações que atuam tanto em área de risco, como as que atuam no gerenciamento de resíduos, que, visando a realização de uma atividade de forma sustentável, tem exigências altas, o que leva a um alto custo em maquinários e licenças para funcionamento (FARIA, 2002).

A organização pesquisada atua viabilizando a sustentabilidade de seus clientes. A fim de viabilizar a sustentabilidade para outras organizações, a organização pesquisada é exigida pelos governos e sociedade a realizar sua atividade de forma sustentável, o que implica em altos investimentos em imagem, maquinários, recursos humanos, dentre outros. Estes custos, bem como a dificuldade de obter licenças formam uma grande barreira de entrada no setor (BENSEN et al., 2010).

As barreiras de entrada do setor de manuseio de resíduos, como apontado por Besen et al. (2010), são no sentido de garantir a atividade de forma sustentável, somente podendo atuar no setor, organizações que possuem ações sustentáveis, uma vez que organizações as quais não investem em sustentabilidade não conseguem captar clientes que, por lei, necessitam contratar organizações ditas sustentáveis para a realização das atividades demandadas. 
Neste sentido, através da fala dos entrevistados, percebe-se que estes consideram a organização como sustentável, o que foi identificado na observação dos processos e conversas, em que foi mostrado ao pesquisador que a organização está preocupada com a preservação da natureza e com a sociedade ao realizar constantes análises de riscos, preocupar-se com a realização dos processos de forma segura, bem como se preocupar com a utilização de tecnologias limpas, até mesmo as que não são exigidas pela legislação, como por exemplo, os carros movidos a Diesel. A preocupação com os funcionários oriundos, em sua maioria, do bairro vizinho à organização, Nova Rosa da Penha, por meio da realização de projetos sociais e melhorias urbanas no local, também são fatores que influenciam para que os entrevistados vejam a organização como sustentável.

A organização estudada entende que possui ações sustentáveis pois sua atividade fim é realizada do mesmo modo como visto nos casos anteriores (HART, 1995. BARTOLOMEO; SILVA; FONSECA, 2014; PIRES; FISHER, 2014; REZENDE; NUNES; PORTELA, 2008), levando-se em consideração a natureza e a sociedade para o alcance do lucro. A organização pesquisada possui ainda, além das constantes avaliações de riscos e melhorias nos processos, a preocupação de lançar no mercado serviços cada vez mais sustentáveis, com o mínimo de prejuízo para o meio ambiente e sociedade, bem como o aproveitamento de resíduos até então inutilizáveis, como o chorume e sucos industriais.

A organização possui ações que beneficiam a natureza e a sociedade, as quais foram constatadas pelo pesquisador, porém, a sustentabilidade plena, tal qual é conceituada por Elkingston (2004) não é alcançada, pois, para tanto, é necessário, segundo o autor, o equilíbrio perfeito entre: natureza, sociedade e lucratividade, o que não ocorre. Tal equilíbrio não é atingido, pois a função da organização é prover a sustentabilidade para outros, sendo este um negócio lucrativo. Ações de cunho sustentável são realizadas, porém, estas visam o lucro como elemento principal, sendo a natureza e a sociedade utilizadas de forma estratégica para a legitimação deste.

O tripé da sustentabilidade (ELKINGSTON, 2004) exige que os três elementos (lucro, natureza e sociedade) sejam tratados com equidade. O que ocorre é a valorização da natureza e sociedade, considerando-se a sua importância, porém, não a equidade, o que não é possível de se alcançar, enquanto benefícios sociais e ambientais forem utilizados para a obtenção de lucro.

\section{CONSIDERAÇÕES FINAIS}

O presente trabalho teve como objetivo descrever e analisar como as estratégias organizacionais se relacionam com a lucratividade e a sustentabilidade no contexto de um aterro sanitário. 
$\mathrm{Na}$ constante busca pelo diferencial competitivo e pela lucratividade, a organização busca informações no mercado, observa a realidade em que está inserida e tenta se destacar. A organização teve sua fundação oferecendo um serviço inédito, de forma pioneira, e quando percebe a entrada de novos concorrentes, que passam a realizar a mesma atividade que ela, busca a estratégia de diferenciação, realizando melhorias nos serviços já existentes, utiliza também das barreiras de entrada do setor, como licenças e altos custos, para evitar os novos entrantes. Com o passar do tempo, porém, esses novos entrantes acabam por romper as barreiras de entrada e a se estabelecer no mercado, o que leva a organização a investir novamente em um novo serviço. As estratégias de inovação e diferenciação ocorrem em fases separadas na organização, enquanto que as estratégias de diversificação e imagem ocorrem a todo o momento.

As estratégias utilizadas conferem à organização vantagem competitiva, sendo esta alcançada pelas estratégias de diferenciação e inovação, a levando ao pioneirismo, enquanto que a diversificação e a imagem a levam à legitimidade. As análises do mercado e os investimentos constantes em processos exclusivos e diferenciados, que não são desenvolvidos por outras organizações, foram identificados como sendo as principais ações gerenciais da organização, norteando as estratégias que buscam a vantagem competitiva.

As estratégias se relacionam com a lucratividade, pois tendo em vista o diferencial competitivo alcançado, esta organização se destaca no mercado, trazendo soluções inovadoras, que podem ser oferecidas a um alto custo para o mercado, que está disposto a custear.

Ao realizar um paralelo entre a estratégia e a sustentabilidade, percebe-se que o tema é bastante discutido internamente, havendo uma real preocupação em relação a este e acreditando-se que há a realização de uma atividade sustentável pelo fato de e organização trazer benefícios para o meio ambiente e para a natureza.

A sustentabilidade é buscada através da realização de sua atividade fim, levando em consideração o que exige a legislação e muitas vezes indo além desta. Porém, o conceito de sustentabilidade, definido por Elkingston (2004), amplamente discutido na conferência RIO 92 e adotado pela ONU (2009), é o equilíbrio perfeito entre lucro, natureza e sociedade, o que não é encontrado na organização.

O equilíbrio não ocorre, pois a função fim da organização é a busca do diferencial competitivo e da lucratividade. As ações gerenciais são realizadas no intuito da criação e manutenção da vantagem competitiva. As estratégias organizacionais acompanham o mercado, são influenciadas por este e o influenciam, sempre na busca pela lucratividade. 
As ações organizacionais buscam o diferencial competitivo, o que não significa que não valorizem o meio ambiente e a sociedade. O presente trabalho pôde constatar que a organização tem grande preocupação em realizar seus processos de forma responsável, realizando constantes análises de risco, e trazendo tecnologias limpas, que beneficiam o meio ambiente. Há também a geração de benefícios sociais, com projetos para os bairros vizinhos, bem como a promoção da educação ambiental, com constantes discussões a respeito do assunto.

Ações que buscam o benefício social e ambiental são promovidas, porém a sustentabilidade é impossibilitada pelo fato da lucratividade ter maior peso do que os outros fatores. A natureza e a sociedade funcionam como suporte para a lucratividade, legitimando seu alcance, no sentido de a organização ser vista como lucrativa, porém, tal lucratividade é legitimada pelo fato de serem promovidas ações socialmente e ambientalmente responsáveis.

Levando em consideração o conceito de sustentabilidade proposto por Elkingston (2004), o presente trabalho não encontra o equilíbrio entre lucratividade e sustentabilidade no contexto estudado. O que se constata é a relação das ações gerenciais com ações sustentáveis, que são propostas em Hart (1995) e em North (1993), ao traçar um paralelo entre sustentabilidade e estratégia. O lucro é o objetivo final da organização, porém não é buscado de forma indiscriminada, pois leva em consideração os elementos naturais e sociais.

A respeito do paralelo traçado entre sustentabilidade e estratégia (NORTH, 1993; HART, 1995) e o não equilíbrio entre os três elementos propostos por Elkingston (2004), coloca-se também em dúvida se é possível o alcance da sustentabilidade em uma organização com fins lucrativos. Propõe-se novos estudos, que analisem a sustentabilidade em organizações de outros setores, e não do sustentável em si, sendo esta uma limitação deste trabalho, que não analisa, por exemplo, a sustentabilidade nos clientes da organização os quais terceirizam esta responsabilidade, por não estarem inseridos no setor.

Cabe então a reflexão sobre o real sentido de se discutir sobre sustentabilidade em uma organização com fins lucrativos, se ela de fato ocorre e se é possível, no atual sistema, que aponta como principal função organizacional o alcance da vantagem competitiva e do lucro, haver o equilíbrio pleno entre natureza, sociedade e lucro. 


\section{REFERÊNCIAS}

AREND, R. J.; LÉVESQUE, M. Is the resource-based view a practical organizational theory? Organization Science, v. 21, n. 4, p. 913-930, 2010.

AZEVEDO, J.; VON ENDE, M.; WITTMANN, M. Responsabilidade social e a imagem corporativa: o caso de uma empresa de marca global. Revista Eletrônica de Estratégia \& Negócios, v. 9, n. 1, p. 95-117, 2016.

BARDIN, L. Análise de conteúdo. Lisboa: Edições 70. 2006.

BARTOLOMEO, S.; SILVA, E.; FONSECA, C. Sustentabilidde na organização contemporânea brasileira: Uma análise literária sob o planejamento estratégico. Revista Científica Hermes, n. 11, p. 169-189, 2014.

BESEN, R.; GÜNTHER, W.; RODRIGUEZ, A.; BRASIL, A. Resíduos sólidos: vulnerabilidades e perspectivas. In: VORMITTAG, E.; SALDIVA P. (Org.). Meio ambiente e saúde: o desafio das metrópoles. São Paulo: Ex Libris Comunicação Integrada, p. 106-123. 2010.

BRONDANI, C.; HENZEL, M. Análise sobre a conscientização ambiental em escolas da rede municipal de ensino. Revista Brasileira de Educação Ambiental, v. 5, n 1, p. 37-44, 2010.

CIRELLI, G.; KASSAI, J. Análise da percepção sobre sustentabilidade por parte de stakeholders de uma instituição financeira: um estudo de caso. 10 Congresso USP de Controladoria e Contabilidade. Anais... Retrieved. Julho, 2010.

DENZIN, N. The discipline and practice of qualitative research. In: DENZIN, Dans N. K.; LINCOLN, Y. S. (Org.).

The landscape of qualitative research: theories and issues. 2. ed. p. 1-45, 2003.

ELKINGSTON, J. Enter the Triple Bottom Line. In: HENRIQUES, A.; RICHARDSON, J. The Triple Bottom Line: Does it All Add Up? Assessing the Sustainability of Business and CSR. London. Earthscan Publications, p. 1-16, 2004.

FARIA, F. Índice da Qualidade de Aterros de Resíduos Urbanos - IQA. Dissertação de M.S., COPPE/UFRJ, Rio de Janeiro, RJ, Brasil. 2002.

FLICK, U. Triangulation in Qualitative Research, In: FLICK, U.; KARDORFF, E.; STEINKE, I (Org.). A Companion to Qualitative Research, Sage, p. 178-183, 2005. 
FRIEDMAN, M. The social responsibility of business is to increase its profits. New York Times Magazine, $v$. 13, 1970.

FRIEDMAN, M. Consumer Boycotts - effecting change trough the marketplace and the media. KLEIN, J. G., SMITH, N. C. E., JOHN, A. Why we boycott: consumer motivations for boicott participation. Journal of Marketing, n. 68, p. 92-109, 1999.

GARCIA, A.; MORAIS, C.; PAVANELI, K.; SCATENA JUNIOR, S. A importância da responsabilidade socioambiental e da logística reversa como estratégia competitiva para as empresas. Organizações e Sociedade, v. 5, n. 3, p. 78-87, 2016.

GASKELL, G. Entrevistas individuais e focais. In: BAUER, M; GASKELL, G. Pesquisa qualitativa com texto, imagem e som: um manual prático. 7. ed. Petrópolis: Editora Vozes, 2008.

HART, S. A natural-resource-based view of the firm. Academy of Management Review, v. 20, n. 4, p. 9861014, oct. 1995.

HEPPER, E.; HANSEN, P.; SANTOS, J. Iniciativas Sustentáveis e Desempenho Organizacional: Uma Análise das Publicações na Base Web of Science. Revista de Gestão Ambiental e Sustentabilidade, p. 98-114, 2016.

HITT, M.; IRELAND, R.; HOSKISSON, R. Administração estratégica. São Paulo: Cengage Learning. 2008.

HOBSBAWN, E. A era dos extremos: o breve século XX. 1941-1991. São Paulo: Companhia das Letras. 1995.

HUSTED, B.; ALLEN, D. Corporate social strategy: Stakeholder engagement and competitive advantage. EUA: Cambridge University Press, 2010.

MAIA, A.; PIRES, P. Uma compreensão da sustentabilidade por meio dos níveis de complexidade das decisões organizacionais. RAM - Revista de Administração Mackenzie, n. 12, v. 3, p. 177-206. 2011.

MCWILLIAMS, A.; SIEGEL, D. Creating and Capturing Value: Strategic Corporate Social Responsibility, Resource-Based Theory, and Sustainable Competitive Advantage. Journal of Management, v. 37, n. 5, p. 1480-1495, 2011.

NORTH, D. Desempeño económico en el transcurso de los años. Conferência de Douglass C. North em Estocolmo, Suécia, dez. 1993.

ONARAN, O. The crisis of capitalism in Europe, West and East. Monthly Review. 2010. 
ONU - ORGANIZAÇÃO DAS NAÇÕES UNIDAS. Resolution 1888. CS/RES/1888, 30/09/2009 - 2009.

PATTI, F.; SILVA, D.; ESTENDER, A. A importância da sustentabilidade para a sobrevivência das empresas. Revista Terceiro Setor \& Gestão-UNG, v. 9, n. 1, p. 18-34, 2015.

PENTEADO, H. Ecoeconomia: uma nova abordagem. São Paulo: Lazuli. 2003.

PIRES, F.; FISCHER, A. Integração entre gestão de pessoas e estratégia de sustentabilidade: O caso da natura. Revista de Gestão social e ambiental. RGSA, São Paulo, v. 8, n. 1, p. 54-72, jan./abr., 2014.

REZENDE, I.; NUNES, J.; PORTELA, S. Um estudo sobre o desempenho financeiro do índice bovespa de sustentabilidade empresarial. REPeC - Revista de Educação e Pesquisa em Contabilidade, Brasília, v. 2, n. 1, p. 71-93, jan./abr. 2008.

RUMELT, R.; SCHENDEL, D.; TEECE, D. Fundamental issues in strategy. In: (Org.). Fundamental issues in strategy: a research agenda. Cambridge: Harvard University Press, 1994.

SACHS, J. A riqueza de todos: a construção de uma economia sustentável em um planeta superpovoado, poluído e pobre. Rio de Janeiro: Nova Fronteira. 2008.

SENGE, P. ; SMITH, B.; KRUSCHWITZ, N.; SCHLEY, S.; LAUR, J. A revolução decisiva: como indivíduos e organizações trabalham em parceria para criar um mundo sustentável. Rio de Janeiro: Campus Elsevier. 2009.

SETH, A.; THOMAS, H.; theories of the firm: Implications for strategy research. Journal of Management Studies, n. 31, p. 165-191, 1994.

TRIVIÑOS, A. Introdução à pesquisa em ciências sociais: a pesquisa qualitativa em educação. São Paulo: Atlas. 1987.

VEIGA, L. G. N.; TORTATO, U. Visão baseada em recursos e sustentabilidade: o paradoxo da proteção de estratégias sustentáveis e as oportunidades do compartilhamento de recursos. RAIMED - Revista de Administração IMED, n. 4, v. 2, p. 220-232, 2014.

VASCONCELOS, G.; ALVES, A.; PESQUEUX, Y. Responsabilidade Social Corporativa e desenvolvimento Sustentável: Olhares habermasianos. Revista de Administração de Empresas - RAE, São Paulo, v. 52, n. 2, p. 148-152, mar./abr. 2012. 
VASCONCELOS, K.; SILVA JUNIOR, A; SILVA, P. Educação gerencial para atuação em ambientes de negócios sustentáveis: desafios e tendências de uma escola de negócios brasileira. RAM - Revista de Administração Mackenzie, v. 14, n. 4, p. 45-75. 2013.

VIZEU, F.; MENEGHETTI, F.; SEIFERT, R. Por uma crítica ao conceito de desenvolvimento sustentável. Cadernos EBAPE. BR, v. 10, n. 3, p. 569-583, 2012.

WERNERFELT, B. A resource-based view of the firm. Strategic Management Journal, v. 5, p. 171-180, 1984.

YIN, R. Estudo de Caso. Porto Alegre: Bookman, 2005.

ZACCARELLI, S. FISCHMANN, A. Estratégias genéricas: classificação e usos. Revista de administração de empresas, São Paulo: FGV, v. 34, n. 4, p. 13-22. 1994. 